\title{
A Maximum Power Point Detection Method for Photovoltaic Module Based on Lambert W Function
}

\author{
Haitao Wu $\mathbb{D}^{1,2}$ and Lele Peng $\mathbb{D}^{3}$ \\ ${ }^{1}$ School of Electrical Engineering, Chongqing University, No. 174 Shazhengjie, Shapingba, Chongqing 400044, China \\ ${ }^{2}$ School of Robot Engineering, Yangtze Normal University, No. 16 Juxian Road, Chongqing 408100, China \\ ${ }^{3}$ School of Urban Railway Transportation, Shanghai University of Engineering Science, No. 333 Longteng Road, \\ Shanghai 201620, China
}

Correspondence should be addressed to Haitao Wu; wht29@163.com and Lele Peng; peter.peng_01@139.com

Received 22 May 2018; Accepted 31 July 2018; Published 9 October 2018

Academic Editor: Venkatesh Vijayaraghavan

Copyright (C) 2018 Haitao Wu and Lele Peng. This is an open access article distributed under the Creative Commons Attribution License, which permits unrestricted use, distribution, and reproduction in any medium, provided the original work is properly cited.

In order to verify the maximum power point tracking algorithm and evaluate, simulate, and optimize photovoltaic system, the maximum power point needs to be detected. In this paper, a maximum power point detection method for photovoltaic (PV) module based on Lambert $\mathrm{W}$ function is presented to achieve the high-precision detection. By using piecewise curve-fitting method, a maximum power point detection and optimization algorithm based on Lambert W function is proposed. Meanwhile, the characteristics of the DC-DC converter used for detection are analyzed in detail, and the working conditions of the converter which can realize full range detection are obtained. Moreover, the performance of the proposed method is investigated by modeling, simulation, and experiment of PV system. Furthermore, errors and statistical analyses are carried out to illustrate the precision of the proposed method. The results validate the model well with experimental work. Compared with previous methods in other works, the results demonstrate the proposed method correctness and effectiveness.

\section{Introduction}

Recently renewable energy power generation have become the subject of intense research. As an important part of renewable energy power generation, PV power generation has also become one of the research hotspots. One of the fundamental issues is to improve the conversion efficiency of solar radiation energy to electricity and reduce power generation costs. However, due to only one and unique particular maximum power point for PV module at specified irradiance and temperature, it is necessary to detect the maximum power point in specific conditions to improve conversion efficiency $[1,2]$. The traditional PV module maximum power point detection technology is to obtain the output characteristic curve by using the polynomial numerical fitting or the curve approximation method by continuously collecting the output voltage and current value of PV module and using the Newton iteration method to deduce the maximum power point of the PV module [37]. Although this method can guarantee the accuracy of the fitting curve through a large amount of experimental data, in practice, the accuracy of the fitting curve is poor (less than $10 \%$ ) because of the inaccuracy of the sampling data itself or the unreasonable sampling point. As a result, there is a certain deviation between the calculated maximum power point and the real maximum power point, and the output power of $\mathrm{PV}$ module cannot be maximized. At the same time, when the Newton iterative method is used to solve the extreme value of the polynomial, the algorithm is not convergent because the selection of the initial value is not suitable or the target deviation and the step length are not correct. Thus, it makes the maximum power point detection fail.

In order to realize the detection of the maximum power point of the high-precision PV module and avoid the failure of the algorithm, a maximum power point detection and optimization algorithm based on the Lambert W function 


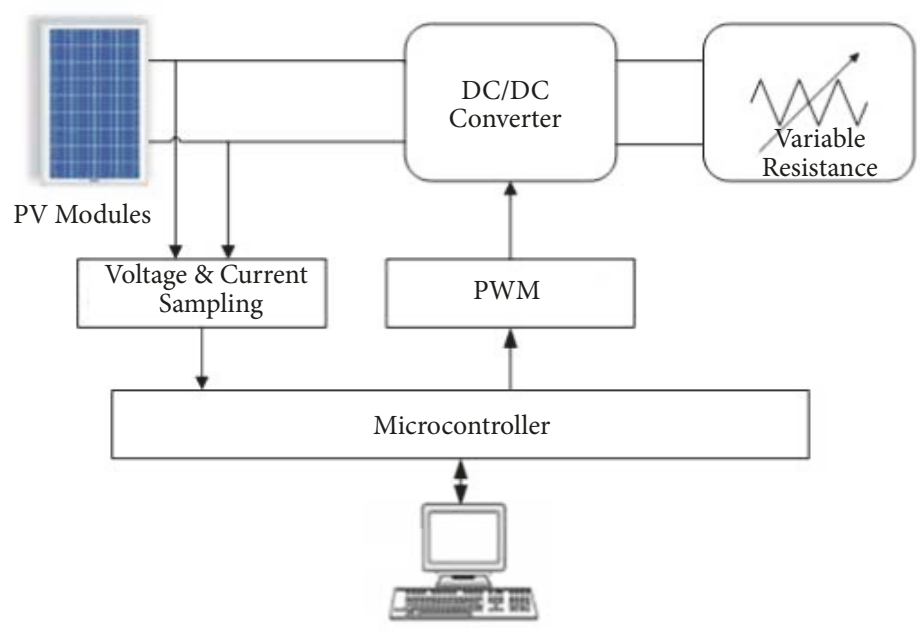

FIGURE 1: Identification of the maximum power point in PV systems.

is proposed. Then the PV module detection system is established to verify the PV module proposed in this paper. The structure and algorithm of the high power point detection system are reasonable.

\section{Maximum Power Point Detection Structure for PV Module}

The maximum power point detection structure of PV module is shown in Figure 1. The system is composed of PV module, DC/DC converter, adjustable load, voltage and current sampling circuit, DSP controller, PWM drive circuit, and PC machine. The PC machine monitors the DSP controller in real time and sends the PWM drive pulse signal to the DC/DC converter to change the impedance of the adjustable load in real time, adjust the voltage and current value of the PV module, and obtain the output voltage and current value of the PV module in different environments. Then, the maximum power point detection and optimization algorithm of PV module based on Lambert $\mathrm{W}$ function is used to get the maximum power point of PV module in the current environment. Therefore, to realize the detection of the maximum power point of the PV module, the key technology can be divided into two points: (1) the DC-DC converter to sample the voltage and current of the PV module and (2) the maximum power point detection and optimization algorithm based on the Lambert $\mathrm{W}$ function.

The DC-DC converter, which sampled the voltage and current of the PV module in real time, essentially changes the output impedance of the PV module and changes the output power of the PV module. At present, the nonisolated DCDC converter mainly includes the Buck converter, the Boost converter, the Buck-Boost converter, the Cuk converter, and the SEPIC converter [8-22]. By changing the duty ratio of the PWM pulse in the switch tube in the converter, the input and output voltage ratio of the nonisolated DC-DC converter also changed, and the output impedance of the PV module also changed. In all the nonisolated DC-DC converters [2, 2027], Buck and Boost converters are widely used in PV systems because of their simple structure and few components.

The Buck converter and the Boost converter have their own characteristics, and the output voltage and current of the PV module changed by selecting the appropriate load; thus the real-time sampling of voltage and current for the PV module can be realized [22-25]. However, considering the difficulty of realizing the actual circuit, Buck and Boost converters still have the following differences:

(1) The size of the energy storage inductor. Under the same ripple current condition, the sensitivity of Buck converter is less than that of Boost converter.

(2) The size of the input capacitance. Under the same power level, in order to guarantee the continuity of input current, the Buck converter needs more input capacitance than Boost.

(3) The complexity of the driving circuit of the switch tube. Because the power transistor in the Buck converter is connected in series, the driving circuit needs to be driven by floating voltage or transformer isolation. This is more complicated than Boost converter.

Therefore, on the basis of fully comparing the characteristics of the two converters and the difficulty of realizing the actual circuit, this paper chooses the Boost converter to realize the real-time sampling of the voltage and current of the PV module.

\section{Maximum Power Point Detection and Optimization Algorithm of PV Module Based on Lambert W Function}

In order to detect the maximum power point of PV module, the conventional method is to sample the output voltage and current value of a large number of PV module, use polynomial fitting or curve approximation to obtain the output characteristic curve of the PV module, and use the 
Newton iterative method to derive the PV module. There are two shortcomings in this method:

(1) the accuracy of the fitted curve (less than 10\%) is caused by the inaccuracy of the sampling data itself or the unreasonable sampling and selection point, thus causing a certain deviation between the maximum power point of the calculated and the real maximum power point, and the energy of the output PV module without maximization.

(2) When using the Newton iterative method to solve the extreme value of the polynomial, the algorithm is often not convergent because the selection of the initial value is not suitable or the target deviation and the step length are incorrect; thus the maximum power point could not be obtained. In this paper, a new algorithm for maximum power point detection and optimization of PV module based on Lambert $\mathrm{W}$ function is proposed. In order to improve the accuracy of sampling data, a piecewise fitting integration method is adopted. In order to avoid the algorithm which does not converge due to the inappropriate initial value and step size, the Lambert $\mathrm{W}$ is used to deduce the analytical solution of the maximum power point of the PV module.

In this paper, the analysis of the PV module parameters and the maximum power point is solved by the Lambert $\mathrm{W}$ function. Then the maximum power point of the solar cell component is obtained by using the polynomial fitting integration method. Finally, in order to prevent the inaccuracy of sampling accuracy caused by the sampling error, the piecewise polynomial fitting method is improved.

3.1. Analytical Formula of Maximum Power Point of PV Module Based on Lambert W Function. The mathematical model of voltage and current characteristics of PV modules is

$$
I=I_{L}-I_{o}\left[\exp \left(\frac{V+I \cdot R_{s}}{n \cdot V_{t h}}\right)-1\right]-\frac{V+I \cdot R_{s}}{R_{p}}
$$

where $I_{L}, I_{O}, R_{s}, R_{s h}$, and $n$ are the photo current, saturation current, series resistance, parallel resistance, and ideality factors of the diodes. $V_{t h}=k T / q$ is the thermal voltage, where $\mathrm{k}$ is the Boltzmann constant equal to $1.38 \times$ $10-23 \mathrm{~J} / \mathrm{K}, \mathrm{T}$ is the kelvin temperature, and $\mathrm{q}$ is the electron charge equal to $1.602 \times 10-19 \mathrm{C}$.

Equation (1) is an implicit transcendental equation and contains five parameters. By using the Lambert $\mathrm{W}$ function, the analytic formula of this formula can be obtained.

$$
V=R_{p}\left(I_{L}+I_{o}-I\right)-R_{s} I-n V_{t h} \cdot W(x)
$$

where

$$
\begin{aligned}
& x=\frac{I_{o} R_{p}}{n V_{t h}} \exp \left(\frac{R_{p}\left(I_{L}+I_{o}-I\right)}{n V_{t h}}\right) \\
& I=\frac{R_{p}\left(I_{L}+I_{o}\right)-V}{R_{s}+R_{p}}-\frac{n V_{t h}}{R_{s}} W(y)
\end{aligned}
$$

where

$$
y=\frac{R_{s} R_{p} I_{o}}{n V_{t h}\left(R_{s}+R_{p}\right)} \exp \left(\frac{R_{p}\left(R_{s} I_{L}+R_{s} I_{o}+V\right)}{n V_{t h}\left(R_{s}+R_{p}\right)}\right)
$$

Equation (2) is integral to the current and reduced [25, 27].

$$
\begin{aligned}
\mathrm{F}(\mathrm{I}, \mathrm{V})= & \int_{0}^{I} V(I) d I \\
= & \frac{1}{2 A}\left[(-V-B I+C)^{2}-(-V+C)^{2}\right]-\frac{1}{2} B I^{2} \\
& +A D I
\end{aligned}
$$

where

$$
\begin{aligned}
& A=R_{p} \\
& B=R_{s}+R_{p} \\
& C=n V_{t h}+R_{p}\left(I_{L}+I_{o}\right) \\
& D=I_{L}+I_{o}
\end{aligned}
$$

By substituting (7), (8), (9), and (10) in (1), we can obtain the following.

$$
\begin{aligned}
R_{p} & =A \\
R_{s} & =B-A \\
n & =\frac{(C-A D)}{V_{t h}} \\
I_{O} & =\frac{D-I-(V+I(B-A)) / A}{\exp [(V+I(B-A)) /(C-A D)]-2} \\
I_{L} & =D-I_{o}
\end{aligned}
$$

The P-V model of PV modules can be obtained by multiplying voltage on both sides (4).

$$
\begin{aligned}
P & =\frac{R_{p}\left(I_{L}+I_{o}\right) V-V^{2}}{R_{s}+R_{p}}-\frac{n(k T / q) V}{R_{s}} \\
& \cdot W\left[\frac{R_{s} R_{p} I_{o}}{n(k T / q)\left(R_{s}+R_{p}\right)}\right. \\
& \left.\cdot \exp \left(\frac{R_{p}\left(R_{s} I_{L}+R_{s} I_{o}+V\right)}{n(k T / q)\left(R_{s}+R_{p}\right)}\right)\right]
\end{aligned}
$$

By means of (11), (12), (13), (14), and (15), we can see that as long as the parameters of $\mathrm{A}, \mathrm{B}, \mathrm{C}$, and D are determined, the unknown parameters in the mathematical model of the PV module can be determined [25]. By using (4) and (16), the voltage and current characteristic curves of PV modules can be depicted.

$P_{m p, c}$ is the theoretical maximum power point, and the analytical formula of $\mathrm{PV}$ power partial conductance at the maximum power point is [25] 


$$
\begin{aligned}
& \left.\frac{\partial P}{\partial V}\right|_{V=V_{m p, c}}=\frac{R_{p}\left(I_{L}+I_{o}\right)-2 V}{R_{s}+R_{p}} \\
& -\frac{n(k T / q) \cdot W\left[\left(R_{s} R_{p} I_{o} / n(k T / q)\left(R_{s}+R_{p}\right)\right) \exp \left(R_{p}\left(R_{s} I_{L}+R_{s} I_{o}+V\right) / n(k T / q)\left(R_{s}+R_{p}\right)\right)\right]}{R_{s}} \\
& -\frac{R_{p} V}{R_{s}\left(R_{s}+R_{p}\right)} \cdot \frac{W\left[\left(R_{s} R_{p} I_{o} / n(k T / q)\left(R_{s}+R_{p}\right)\right) \exp \left(R_{p}\left(R_{s} I_{L}+R_{s} I_{o}+V\right) / n(k T / q)\left(R_{s}+R_{p}\right)\right)\right]}{1+W\left[\left(R_{s} R_{p} I_{o} / n(k T / q)\left(R_{s}+R_{p}\right)\right) \exp \left(R_{p}\left(R_{s} I_{L}+R_{s} I_{o}+V\right) / n(k T / q)\left(R_{s}+R_{p}\right)\right)\right]} \\
& =0
\end{aligned}
$$

Therefore, the analytical formula of voltage power bias is drawn in MATLAB, and the maximum power voltage deviation is zero at the maximum power point. The maximum theoretical power voltage value is found, and the value is replaced by (16). Equation (17) shows that the maximum power voltage value of the theory can be determined as long as parameters of $I_{L}, I_{o}, n, R_{s}$, and $R_{p}$ are determined. Therefore, the solution of the maximum power point of $\mathrm{PV}$ module is reduced to the solution of parameters A, B, C, and D.

\subsection{Solution and Optimization of Maximum Power Point of PV} Module Based on Lambert W Function. Equation (6) shows that the integral of voltage and current of PV module is a polynomial of four elements for A, B, C, and D. As long as we get the integral value of voltage and current at different stages to get four polynomial equations, it is easy to solve the four parameters of A, B, C, and D. In order to precisely fit the output voltage and current characteristics of PV modules, the voltage and current relationship of PV modules is deduced by using the 6-order minimum polynomial fitting [15]. Set the voltage and current of the sampling point for PV module as $\left(I_{i}, V_{i}\right)(\mathrm{i}=0,1,2,3,4,5,6)$ and the voltage and current sixorder polynomial as follows.

$$
V\left(I_{i}\right)=a_{0}+a_{1} I_{i}+a_{2} I_{i}^{2}+a_{3} I_{i}^{3}+a_{4} I_{i}^{4}+a_{5} I_{i}^{5}+a_{6} I_{i}^{6}
$$

The substitution of (18) in (6) formula can be expressed as follows.

$$
\begin{aligned}
F(I, V)= & a_{0} I+\frac{1}{2} a_{1} I^{2}+\frac{1}{3} a_{2} I^{3}+\frac{1}{4} a_{3} I^{4}+\frac{1}{5} a_{4} I^{5} \\
& +\frac{1}{6} a_{5} I^{6}+\frac{1}{7} a_{6} I^{7} \\
= & \frac{1}{2 A}\left[(-V-B I+C)^{2}-(-V+C)^{2}\right]-\frac{1}{2} B I^{2} \\
& +A D I
\end{aligned}
$$

Taking the 2- norm as the overall error in the fitting algorithm, the total error is square.

$$
\begin{aligned}
e^{2} & =\|e\|_{2}^{2}=\left(\sqrt{\sum_{i=0}^{5}\left[V\left(I_{i}\right)-V_{i}\right]^{2}}\right)^{2} \\
& =\sum_{i=0}^{5}\left[V\left(I_{i}\right)-V_{i}\right]^{2}
\end{aligned}
$$

In order to minimize the overall error, the partial derivative of PV voltage and current in sampling points is 0 .

$$
\begin{aligned}
f(i, v) \frac{\partial S}{\partial a_{j}}=2 \sum_{i=0}^{6}\left(\sum_{k=0}^{6} a_{k} I_{i}^{k}-V_{i}\right) I_{i}^{j}= & , \\
& j=0,1, \cdots, 6
\end{aligned}
$$

Equation (21) can be simplified to

$$
\sum_{i=0}^{6}\left(\sum_{k=0}^{6} I_{i}^{j+k}\right) a_{k}=\sum_{i=0}^{m} I_{i}^{j} V_{i}, \quad j=0,1, \cdots, 6 .
$$

Set

$$
\begin{aligned}
Y & =\left[\begin{array}{c}
\sum_{i=0}^{6} V_{i} \\
\sum_{i=0}^{6} I_{i} V_{i} \\
\vdots \\
\sum_{i=0}^{6} I_{i}^{6} V_{i}
\end{array}\right] \\
X & =\left[\begin{array}{cccc}
6+1 & \sum_{i=0}^{6} I_{i} & \cdots & \sum_{i=0}^{6} I_{i}^{6} \\
\sum_{i=0}^{6} I_{i} & \sum_{i=0}^{6} I_{i}^{2} & \cdots & \sum_{i=0}^{6} I_{i}^{7} \\
\vdots & \vdots & & \vdots \\
\sum_{i=0}^{6} I_{i}^{6} & \sum_{i=0}^{6} I_{i}^{7} & \cdots & \sum_{i=0}^{6} I_{i}^{12}
\end{array}\right]
\end{aligned}
$$




$$
\theta=\left[\begin{array}{c}
a_{0} \\
a_{1} \\
\vdots \\
a_{6}
\end{array}\right] .
$$

The output matrix can be represented as follows.

$$
Y=X \theta
$$

Then the parameter matrix can be expressed as follows.

$$
\theta=X^{-1} Y
$$

Thus, as long as seven sampling points on the voltage and current curve are obtained, the 6-order polynomials for fitting PV modules can be obtained. The value of the use (19) can be obtained. As the output characteristics of the PV module are similar to the first-order impulse response, the 7 experimental sampling points used for curve fitting can be obtained by the following methods, as is shown in Figure 2.

$$
\begin{aligned}
& I_{0}=\tan \theta_{1} I_{m p} \\
& I_{1}=\frac{1}{2} I_{m p}\left[1-\frac{1}{4}(1-\cos \theta)\right] \\
& I_{2}=I_{m p}-\frac{1}{4}(1-\cos \theta) I_{m p} \\
& I_{3}=I_{m p} \\
& I_{4}=I_{m p}+\frac{1}{4}(1-\cos \theta)\left(I_{s c}-I_{m p}\right) \\
& I_{5}=\frac{1}{2} I_{s c}-\frac{1}{2}\left[I_{m p}+\frac{1}{4}(1-\cos \theta)\left(I_{s c}-I_{m p}\right)\right] \\
& I_{6}=\tan \theta_{2} I_{s c}
\end{aligned}
$$

In order to avoid the reduction of fitting accuracy due to improper selection of data, the points used for $F(I, V)$ calculation are $\left(I_{0}, V_{0}\right),\left(I_{2}, V_{2}\right),\left(I_{4}, V_{4}\right)$, and $\left(I_{6}, V_{6}\right)$. The four sampling points are substituted into (19), and the parameters A, B, C, and D can be obtained, so that by (17) the maximum power point can be obtained. However, the seven sampling points for the fitting of the calculation may also cause the error due to the inaccuracy of the sampling precision. In order to overcome the problem, the seven sampling points are also obtained by polynomial fitting calculation, respectively, as is shown in Figure 3 [25].

\section{Experimental Verification}

In order to verify the correctness and effectiveness of the $\mathrm{PV}$ module, maximum power point detection technology is proposed in this paper. First of all, according to the structure of the maximum power point detection technology of the PV module, the DC-DC converter and the experimental system based on Boost circuit are set up. The curve fitting and maximum power point solution are carried out and compared with the popular algorithm $[23,24]$. The specific experimental methods, experimental materials, and experimental results are as follows.

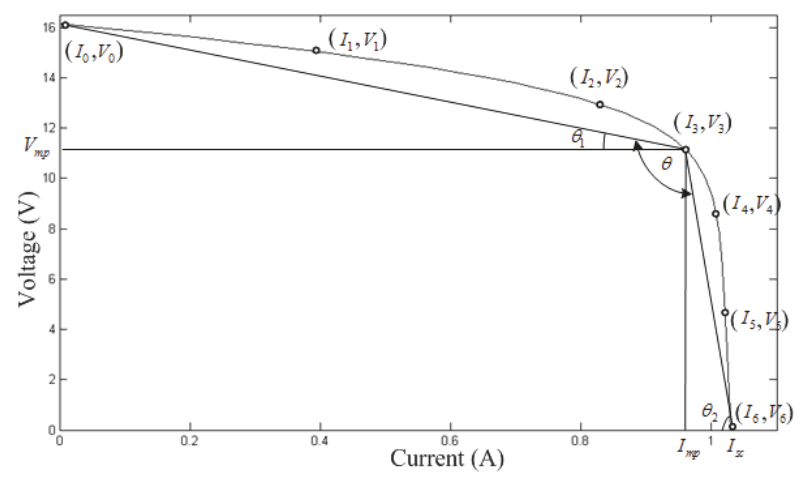

FIGURE 2: The seven sample points used for polynomial curve fitting.

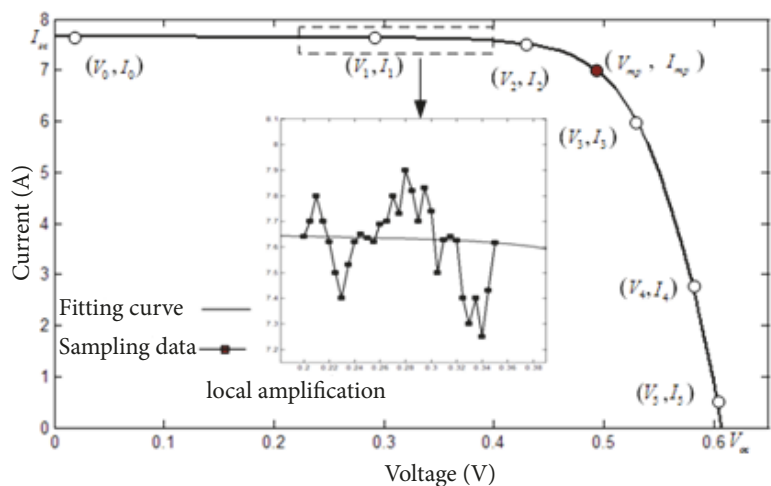

FIgURE 3: The sample points used for polynomial curve fitting.

4.1. Experimental Materials and Methods. According to the structure of maximum power point detection technology of PV module, a voltage and current sampling DC-DC converter and experimental system based on Boost circuit are set up. The experimental system is shown in Figure 4, the parameters of the experimental system are shown in the Table 1, and the parameter setting interface of the experimental system is shown in Figure 4.

In order to verify the correctness and effectiveness of the maximum power point detection technology for $\mathrm{PV}$ module proposed in this paper, the Kyocera KC200GT polycrystalline module [26] was used for the experiment [23, 24]. The error analysis method adopted in this paper is absolute error and root mean square analysis. The absolute error (AE) and normalized root mean square error (NRMSE) at any sampling point are defined.

$$
\begin{aligned}
A E_{i} & =\left|V_{c i}-V_{e i}\right| \\
N R M S E & =\frac{\left[(1 / N) \sum_{i=1}^{N}\left(I_{i, \exp }-I_{i, c a l}\right)^{2}\right]^{1 / 2}}{(1 / N) \sum_{i=1}^{N} I_{i, \exp }}
\end{aligned}
$$

where N, NRMSE, $I_{i, \text { exp }}$, and $I_{i, c a l}$ are the number of sampling points, normalized root mean square error, output current of photovoltaic module by experimental, and calculated current values of photovoltaic module.

The experimental methods are as follows: Firstly, the output voltage and current (I-V) and voltage power curve 
TABLE 1: Parameters of experimental system.

\begin{tabular}{lccccc}
\hline $\begin{array}{l}\text { Power } \\
\text { Transistor }\end{array}$ & Inductance & $\begin{array}{c}\text { Output } \\
\text { Capacitance }\end{array}$ & Driver & Microcontroller & PV Simulator \\
\hline SPW47N60 & $2 \mathrm{mH}$ & $1000 \mathrm{uF} / 450 \mathrm{~V}$ & TLP350 & TMS320F28027 & Topcon \\
\hline
\end{tabular}

TABLE 2: Parameters for the polycrystalline photovoltaic module using different methods under Standard Test Conditions (STC) (measured at $25^{\circ} \mathrm{C}$ and $\left.\mathrm{AM} 1.5(1000 \mathrm{~W} / \mathrm{m} 2)\right)$.

\begin{tabular}{lccc}
\hline Parameters & Ref. [23] & Ref. [24] & Our method \\
\hline$I_{L}(\mathrm{~A})$ & 8.211 & 8.223 & 8.225 \\
$I_{O}(\mathrm{~A})$ & $2.12 \times 10^{-9}$ & $2.15 \times 10^{-9}$ & $7.63 \times 10^{-9}$ \\
$\mathrm{n}$ & 1.0758 & 1.0758 & 1.1441 \\
$R_{s}(\Omega)$ & 0.233 & 0.308 & 0.196 \\
$R_{s h}(\Omega)$ & 132.88 & 193.049 & 103.034 \\
NRMSE & 0.0075 & 0.0267 & 0.00068 \\
\hline
\end{tabular}

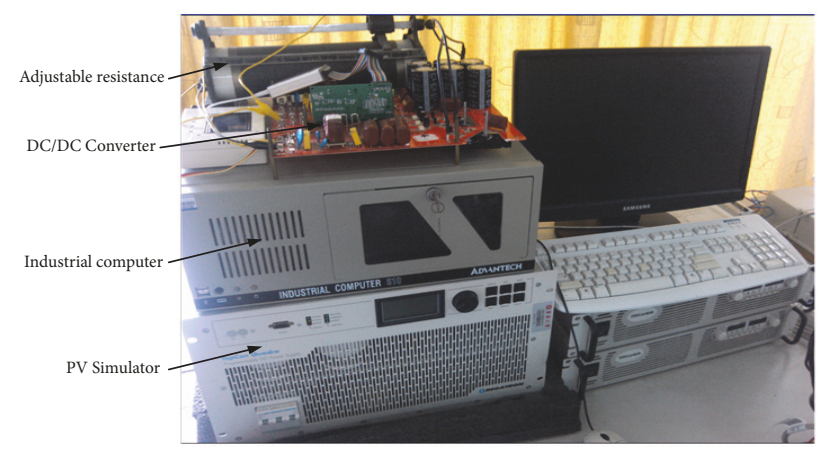

FIGURE 4: The experimental system.

(P-V) of the PV module are simulated in the PV analog power supply according to the parameters of the required PV module. Secondly, using the constructed PV module voltage and current detection system, the control instruction is sent to the DSP controller through the upper computer, and the output impedance of the PV module is constantly changed; thus the PV output power is adjusted, the voltage and current values of the corresponding PV module are collected, and the voltage and current values coexist in the MATLAB. At the end, the maximum power point of PV module is obtained by using the maximum power point detection and optimization algorithm based on the Lambert $\mathrm{W}$ function.

4.2. Experimental Results and Discussion. The maximum power point detection system of PV module and the maximum power point detection and optimization algorithm based on Lambert $\mathrm{W}$ function are used to detect the different types of PV module system, respectively. The results of the experiment are shown in Table 2, and the corresponding test curves are shown in Figures 5-8.

Figures 5 and 6 show the experimental data of KC200GT polycrystalline module and the curve of fitting data in the output voltage and current characteristics and power and voltage characteristics. Figures 5 and 6 show that the way to change the duty ratio by sending instructions through the upper computer to the DSP controller is to change the output characteristics of the solar cell and PV module. Figures 5 and 6 further show that the maximum power point detection and optimization algorithm of PV module based on Lambert W function can be used to detect the maximum power point of the solar cell and PV module.

Figures 7 and 8 show the absolute error values of voltage and current and voltage power compared to the maximum power detection and optimization algorithm based on the Lambert $\mathrm{W}$ function and widely used method. Figures 7 and 8 indicate that the maximum power point of the maximum power can be obtained by using the maximum power point detection and optimization algorithm based on the Lambert $\mathrm{W}$ function. Table 2 gives the NRMSE values of different detection methods at the maximum power point. At the same time, it can be seen from Table 2 that, for the maximum power point, the values of the maximum power point detection and optimization algorithm based on the Lambert $\mathrm{W}$ function are less than $0.0059 \mathrm{~A}$ and $0.1604 \mathrm{~W}$, respectively, and the NRMSE is less than 0.00068 . It can also be seen that the maximum power point detection method and optimization algorithm proposed in this paper can obtain a smaller deviation value than other methods and can achieve high-precision detection of maximum power point.

\section{Conclusions}

In this paper, a maximum power point detection method of PV module based on Lambert W function is proposed. Firstly, it analyzes the system structure of the maximum power point detection technology of PV module and points out that the key technical points of realizing the technology are the following: (1) The output voltage and current of PV module are sampled by Boost converter. (2) A maximum power point detection and optimization algorithm based on Lambert $\mathrm{W}$ function is applied to detect the maximum power point of PV module. Secondly, The converter structure of voltage and current sampling for solar cell is analyzed. Thirdly, the maximum power point detection and optimization algorithm based on Lambert W function is proposed, and the solution of maximum power point is derived. Finally, through the construction of the PV module maximum power 


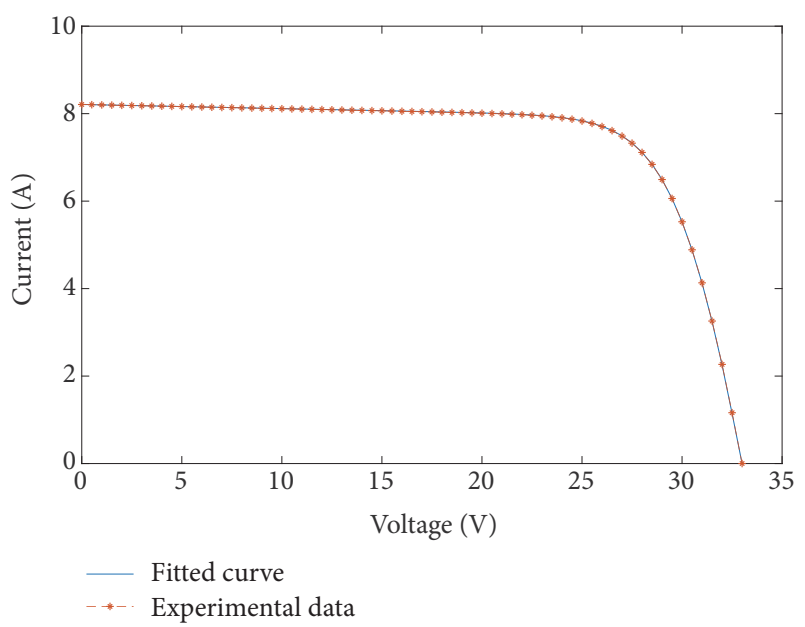

FIgURE 5: Experimental $I-V$ data and the fitted curve for polycrystalline photovoltaic module.

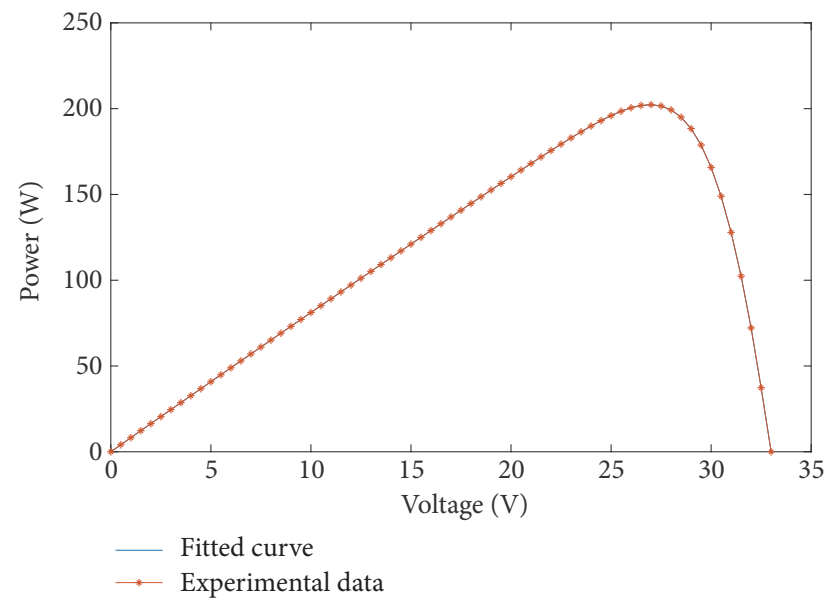

Figure 6: Experimental $P-V$ data and the fitted curve for polycrystalline photovoltaic module.

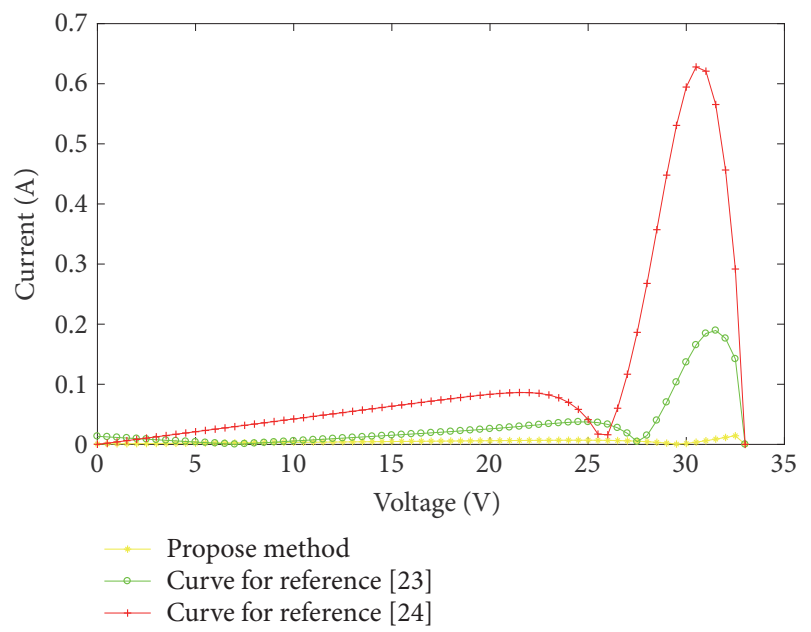

Figure 7: Absolute current errors for polycrystalline photovoltaic module.

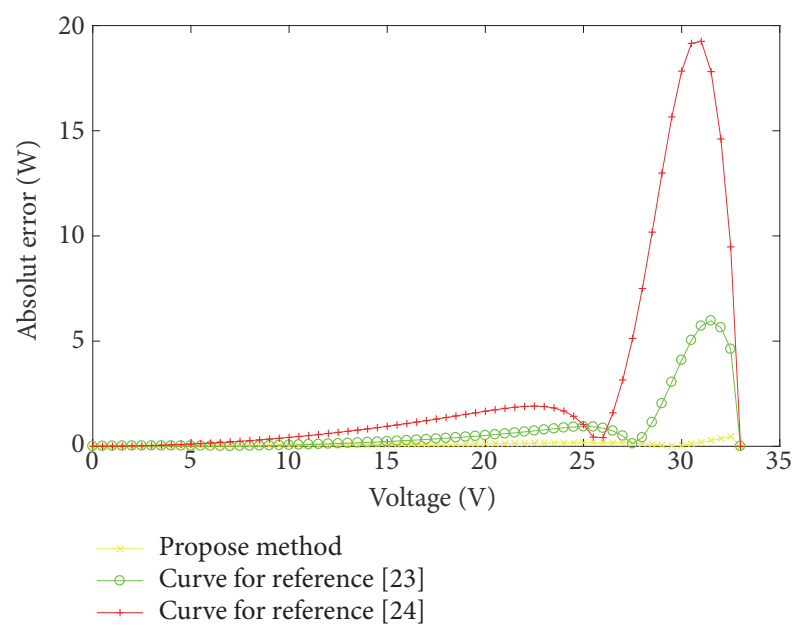

FIGURE 8: Absolute power errors for polycrystalline photovoltaic module.

point detection system, the polycrystalline PV module is tested, and the structure and algorithm of the PV module maximum power point detection system proposed in this paper proved to be reasonable.

\section{Data Availability}

The experiment data used to support the findings of this study are included within the article.

\section{Conflicts of Interest}

The authors declare no conflicts of interest.

\section{Authors' Contributions}

Both authors have carried out simulation (Haitao $\mathrm{Wu}$ and Lele Peng), performed experiments (Lele Peng and Haitao $\mathrm{Wu}$ ), and written and edited the paper (Haitao $\mathrm{Wu}$ and Lele Peng).

\section{Acknowledgments}

This research was supported by the National Natural Science Foundation of China (Grant No. 51478258, 51405287), Shanghai Committee of Science and Technology (Grant No. 18030501300), Special Financial Aid to Postdoctoral Research Fellow in Chongqing (Grant No. 2014086), Science and Technology Research Project of the Chongqing Municipal Education Committee (Grant No. KJ131321), and Science and Technology Research Project of Yangtze Normal University (Grant No. 2013XJ2D004).

\section{References}

[1] M. R. AlRashidi, M. F. AlHajri, K. M. El-Naggar, and A. K. AlOthman, "A new estimation approach for determining the IV characteristics of solar cells," Solar Energy, vol. 85, no. 7, pp. 1543-1550, 2011. 
[2] L. Peng, S. Zheng, X. Chai, and L. Li, "A novel tangent error maximum power point tracking algorithm for photovoltaic system under fast multi-changing solar irradiances," Applied Energy, vol. 210, pp. 303-316, 2018.

[3] K. Ishaque and Z. Salam, "An improved modeling method to determine the model parameters of photovoltaic (PV) modules using differential evolution (DE)," Solar Energy, vol. 85, no. 9, pp. 2349-2359, 2011.

[4] W. De Soto, S. A. Klein, and W. A. Beckman, "Improvement and validation of a model for photovoltaic array performance," Solar Energy, vol. 80, no. 1, pp. 78-88, 2006.

[5] A. Ortiz-Conde, F. J. García Sánchez, and J. Muci, "New method to extract the model parameters of solar cells from the explicit analytic solutions of their illuminated I-V characteristics," Solar Energy Materials \& Solar Cells, vol. 90, no. 3, pp. 352-361, 2006.

[6] W. Xiao, M. G. J. Lind, W. G. Dunford, and A. Capel, "Real-time identification of optimal operating points in photovoltaic power systems," IEEE Transactions on Industrial Electronics, vol. 53, no. 4, pp. 1017-1026, 2006.

[7] M. Chegaar, G. Azzouzi, and P. Mialhe, "Simple parameter extraction method for illuminated solar cells," Solid-State Electronics, vol. 50, no. 7-8, pp. 1234-1237, 2006.

[8] J. L. Santos, F. Antunes, A. Chehab, and C. Cruz, "A maximum power point tracker for PV systems using a high performance boost converter," Solar Energy, vol. 80, no. 7, pp. 772-778, 2006.

[9] M. A. Elgendy, B. Zahawi, and D. J. Atkinson, "Assessment of perturb and observe MPPT algorithm implementation techniques for PV pumping applications," IEEE Transactions on Sustainable Energy, vol. 3, no. 1, pp. 21-33, 2012.

[10] M. Veerachary, "Fourth-order buck converter for maximum power point tracking applications," IEEE Transactions on Aerospace and Electronic Systems, vol. 47, no. 2, pp. 896-911, 2011.

[11] J. Park and S. Kim, "Maximum power point tracking controller for thermoelectric generators with peak gain control of boost DC-DC converters," Journal of Electronic Materials (JEM), vol. 41, no. 6, pp. 1242-1246, 2012.

[12] D. Yang, M. Yang, and X. Ruan, "One-cycle control for a double-input DC/DC converter," IEEE Transactions on Power Electronics, vol. 27, no. 11, pp. 4646-4655, 2012.

[13] K. Djermouni, A. Berboucha, K. Ghedamsi, and D. Aouzellag, "Optimization of a photovoltaic field during faulty and normal operation," Solar Energy, vol. 113, pp. 171-180, 2015.

[14] W. Li and X. He, "Review of non-isolated high-step-up DC/DC convertersin photovoltaic grid-connected applications," IEEE Transactions on Industrial Electronics, vol. 58, no. 4, pp. 12391250, 2011.

[15] M. Uno and A. Kukita, "Single-switch voltage equalizer using multistacked buck-boost converters for partially shaded photovoltaic modules," IEEE Transactions on Power Electronics, vol. 30, no. 6, pp. 3091-3105, 2015.

[16] W. Xiao, N. Ozog, and W. G. Dunford, "Topology study of photovoltaic interface for maximum power point tracking," IEEE Transactions on Industrial Electronics, vol. 54, no. 3, pp. 1696-1704, 2007.

[17] Y. Du and D. D.-C. Lu, "Battery-integrated boost converter utilizing distributed MPPT configuration for photovoltaic systems," Solar Energy, vol. 85, no. 9, pp. 1992-2002, 2011.

[18] N. Mazouz and A. Midoun, "Control of a DC/DC converter by fuzzy controller for a solar pumping system," International Journal of Electrical Power \& Energy Systems, vol. 33, no. 10, pp. 1623-1630, 2011.
[19] S. Dian, X. Wen, X. Deng, and S. Zhang, "Digital control of isolated Cuk power factor correction converter under wide range of load variation," IET Power Electronics, vol. 8, no. 1, pp. 142-150, 2015.

[20] R. Haroun, A. E. Aroudi, A. Cid-Pastor, G. Garíca, C. Olalla, and L. Martínez-Salamero, "Impedance matching in photovoltaic systems using cascaded boost converters and sliding-mode control," IEEE Transactions on Power Electronics, vol. 30, no. 6, pp. 3185-3199, 2015.

[21] C. Y. Huang, K. Itako, T. Mori, and Q. Ge, "MPPT control method using boost type DC-DC converter for PV generation system with mismatched modules," Advanced Materials Research, vol. 918, pp. 171-176, 2014.

[22] N. Femia, D. Granozio, G. Petrone, G. Spagnuolo, and M. Vitelli, "Optimized one-cycle control in photovoltaic grid connected applications," IEEE Transactions on Aerospace and Electronic Systems, vol. 42, no. 3, pp. 954-971, 2006.

[23] N. Maouhoub, "Photovoltaic module parameter estimation using an analytical approach and least squares method," Journal of Computational Electronics, vol. 17, no. 2, pp. 784-790, 2018.

[24] I. Nassar-Eddine, A. Obbadi, Y. Errami, A. El Fajri, and M. Agunaou, "Parameter estimation of photovoltaic modules using iterative method and the Lambert W function: A comparative study," Energy Conversion and Management, vol. 119, pp. 37-48, 2016.

[25] L. Peng, Y. Sun, Z. Meng, Y. Wang, and Y. Xu, "A new method for determining the characteristics of solar cells," Journal of Power Sources, vol. 227, pp. 131-136, 2013.

[26] "KC200GT High Efficiency Multicrystal Photovoltaic Module Datasheet Kyocera," http://www.kyocera.com.sg/products/ solar/pdf/kc200gt.pdf.

[27] H. Fathabadi, "Novel neural-analytical method for determining silicon/plastic solar cells and modules characteristics," Energy Conversion and Management, vol. 76, pp. 253-259, 2013. 


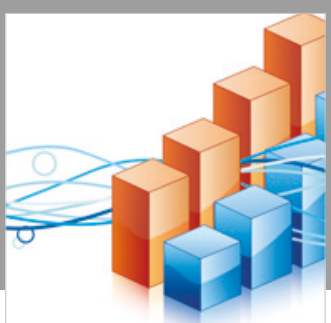

Advances in

Operations Research

\section{-n-m}
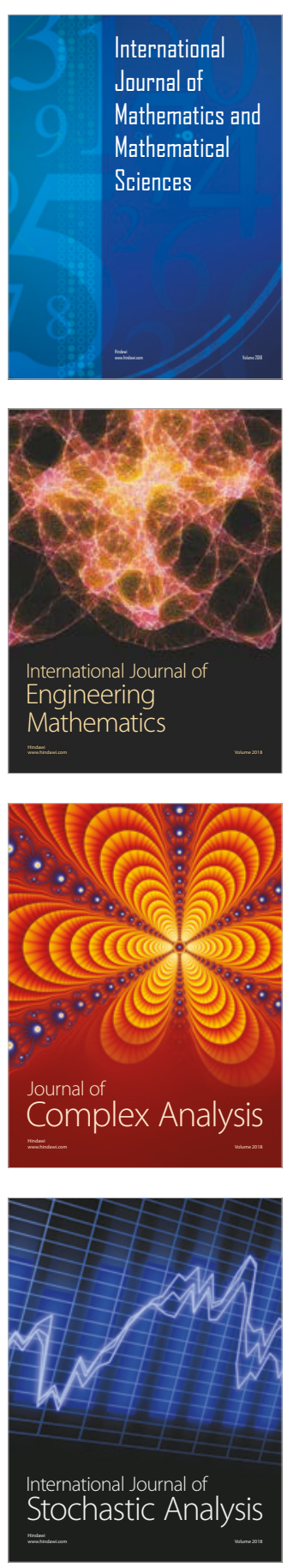
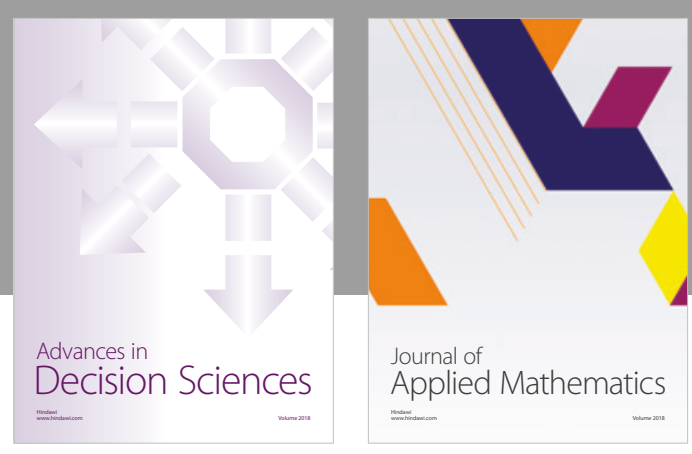

Journal of

Applied Mathematics
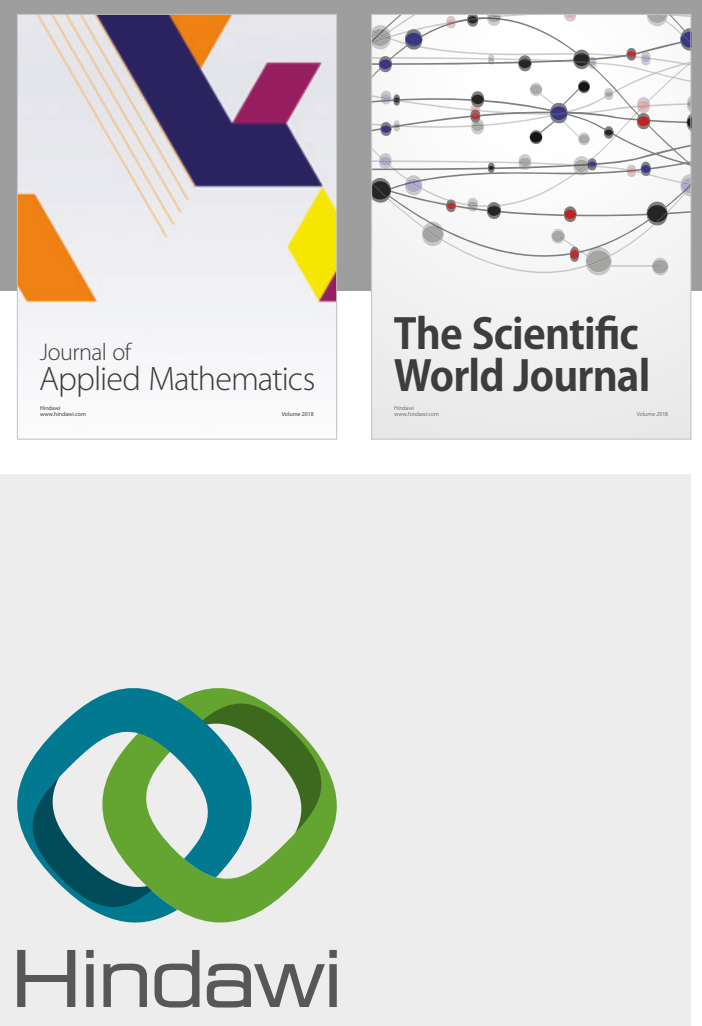

Submit your manuscripts at

www.hindawi.com

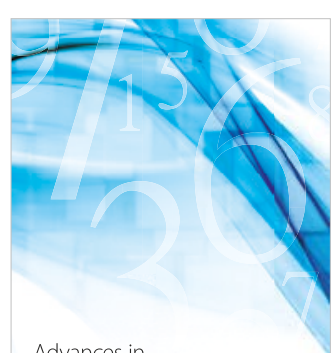

Advances in
Numerical Analysis
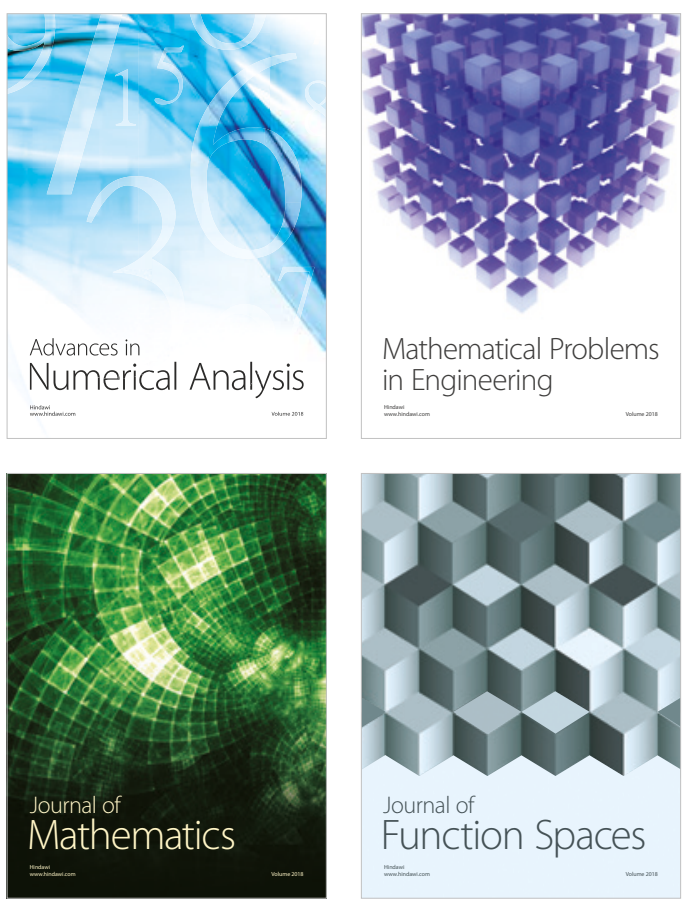

Mathematical Problems in Engineering

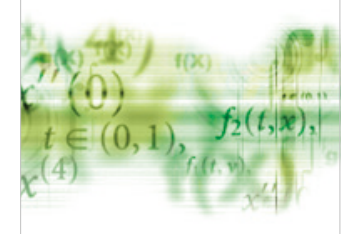

International Journal of

Differential Equations

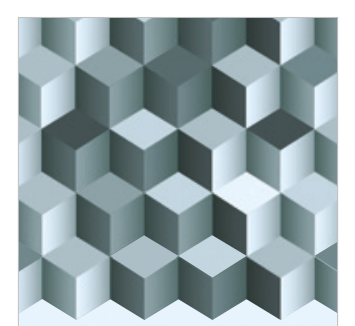

Journal of

Function Spaces

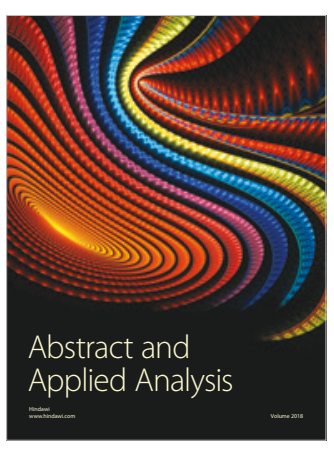

The Scientific

World Journal

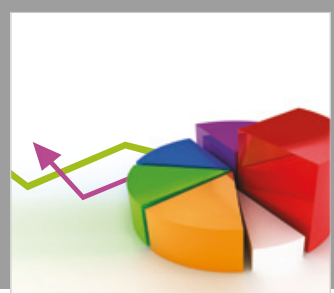

Journal of

Probability and Statistics
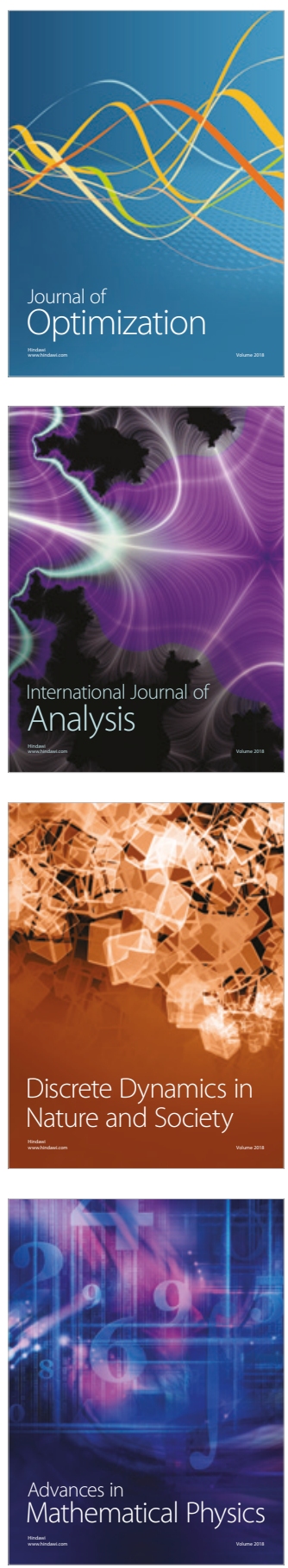